\title{
Real fantástico? 0 deslumbramento científico em Walmor Corrêa
} Fantastic real? The scientific dazzle in Walmor Corrêa

MATHEUS SILVEIRA FURTADO

Universidade de Bras;ilia (UNB), Brasília, Brasil

SARA DE OLIVEIRA LIMA SCHOLZE

Universidade de Bras;ilia (UNB), Brasília, Brasil

\section{RESUMO}

Os limites entre o imaginário da arte e o imaginário da ciência na poética de Walmor Corrêa são praticamente inexistentes. Mais do que uma preferência de ordem temática, essas confluências de seus trabalhos são uma preocupação essencial. Quando o artista se apropria de linguagens e técnicas associadas aos âmbitos da biologia e ilustração científica e reconfigura as formas e características a partir de uma criatura fantástica e exótica, ele proporciona um deslumbramento encantador para o observador, ele cria não apenas um ser, mas também um cenário, uma narrativa, uma forma de catalogá-lo, entendêlo e apresentá-lo aos curiosos. Por meio de seu trabalho sobrevivem aspectos culturais e teóricos que cercam ambas as disciplinas e moldam a compreensão sobre a influência do imaginário do passado consolidado no presente. Assim, este artigo tem por objetivos apresentar e explorar três obras do artista que possuem características permeáveis e sobreviventes, analisando como elas se apropriam dos discursos científicos e museológicos. Para tanto, utiliza-se uma perspectiva metodológica comparativa.

\section{PALAVRA S-CHAVE}

Walmor Corrêa, Imaginário, ciência, fantástico, exótico, arte

\begin{abstract}
A B S T R A C T
In the work of Walmor Corrêa the boundaries between the imaginary of science and the imaginary of art are almost none. More than the preference for a choice of themes, such confluences are an essential subject of his production. By borrowing languages and techniques from biology and scientific illustration, the artist reassembles shapes and characteristics to an exotic and fantastic creature, presenting to the public an amusing astonishment that produces not only a new being, but new scenarios, narratives and ways to analyse, catalog and exhibit it to the public. Through his work, there are cultural and theoretical aspects surviving, which surround both disciplines and shape the comprehension over the influences of the Imaginary in the past over the future. Utilizing a comparative perspective, this article objectives are to present and explore three works by the artist that have such intertwined and surviving characteristics, analysing the way he borrows scientific and museological discourses.
\end{abstract}

\section{KE YWORDS}

Walmor Corrêa, Imaginary, science, fantastic, exotic, art 
Walmor Corrêa ${ }^{1}$ apresenta perspectiva única sobre as relações entre arte, ciência e imaginário. $\mathrm{O}$ artista é explorador de um território da imagética fantástica. Ele deslumbra o olhar do observador, não apenas por uma qualidade primorosa de desenho e figuração da anatomia, mas por perceber e demonstrar a potencialidade que o fantástico, o mítico e o exótico possuem no imaginário coletivo. A partir da visualidade, o espectador é imerso em um universo onde o natural e o ficcional são colocados em um mesmo espaço, permitindo ao espectador questionar-se e encantar-se com o que vê.

O conjunto de obras do artista configura-se por um rigor técnico - seja utilizando-se da pintura, escultura ou desenho - e muitas vezes busca-se uma narrativa visual a partir da disposição dos objetos que remetem a espaços expositivos específicos da ciência. Esta confere ao espectador a possibilidade de se maravilhar ao adentrar em um universo aparentemente documental, mas ao mesmo tempo revela-se uma série de improbabilidades.

Dentro deste corpus, entretanto, trataremos de três obras em que são propostas questões para além do deslumbramento e que dialogam com o tempo, contestando a construção imagética de um Novo Mundo formulado por viajantes europeus do século XVI ao XIX: Natureza Perversa, Biblioteca dos Enganos e Memento Mori. Este recorte pretende uma análise de como Walmor Corrêa explora a visualidade para questionar esses discursos e colocar em fricção o imaginário e a ciência: “(...) a fricção na obra de arte tem a ver com o tipo de contato que faz cintilar o imaginado e o vivido, o lembrado e o esquecido, o ficcional e o fingido, o singular e o assombroso." (CHEREM, 2010, p.913)

\section{Entre exóticos híbridos e pequenos enganos}

Em Natureza Perversa (2003) (fig. 1), brinca-se com o olhar e convida-se o espectador para compartilhar essas perspectivas de "deparar-se e fantasiar-se" com algo irreal. As formas vazam, misturam-se, reconfiguram as noções de completude e reconhecimento, engendrandose em hibridismos, e moldam novas imagens na mente do espectador. Visualizam-se sete pranchas anatômicas em que se descrevem sistemas ósseos supostamente capazes de sustentar um Apterigiformes Aco II ou um Amphibien Mit Schnabel. Além dessas pranchas, somam-se onze estudos bastante detalhados e complexos que descrevem características particulares de cada ser, especificando em minúcias como se organizariam as vísceras, como seriam os hábitos, os filhotes e outras peculiaridades. Junto a eles, também se encontra uma curiosa coleção entomológica disponível para observação através de lupas.

Parte do jogo de montagem de Walmor é trazer para o campo do real criaturas fantásticas que apesar de garantida inexistência, poderiam muito bem figurar num museu de História Natural, se infiltrarem nas exposições e coleções de ossadas, molhados², taxidermizados, imagens e

1 Artista brasileiro contemporâneo, natural de Florianópolis, Santa Catarina. Atualmente trabalha em Porto Alegre, local onde se encontra o seu ateliê. Sua obra visa explorar elementos do imaginário fantástico e folclórico, ao mesmo tempo em que se vale de técnicas e linguagens da Ilustração científica.

2 Fixados - Espécimes preservados em vidros com soluções químicas líquidas tais como formaldeídos, ou álcoois, comumente chamados: molhados. 
convencerem o visitante de seus lugares no mundo. Nesta obra, percebe-se um esforço de convencimento do espectador a partir de cada unidade significativa formulada por texto e imagem presente nas telas. Esse conjunto é apresentado como uma mimese e utiliza-se a linguagem técnica científica para envolver quem a observa e assim proporcionar um fantástico e exótico universo construído.
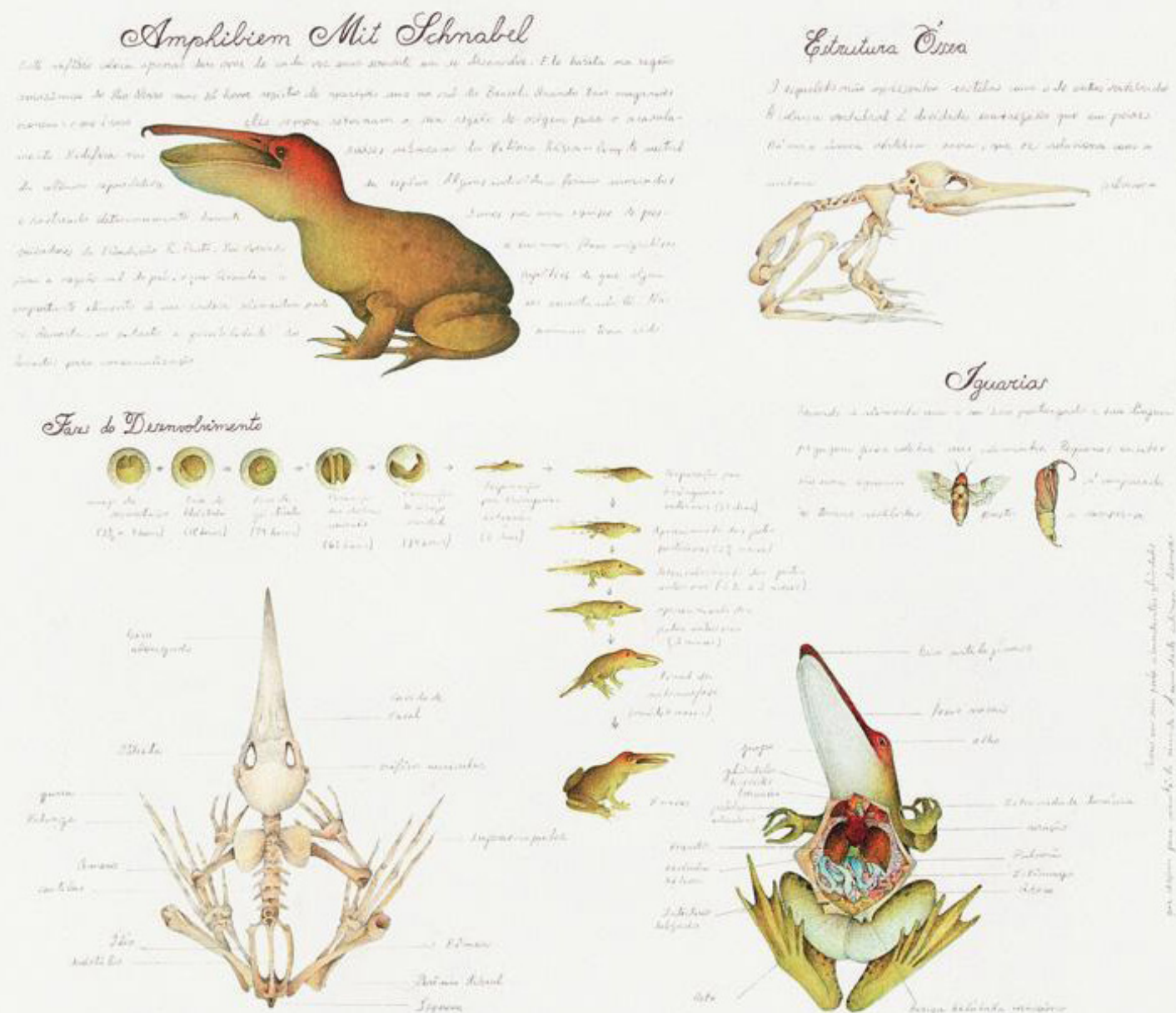

Estrutura Oisea - Pista Supecior

Organizasáa Onterna

Figura 1- Walmor Corrêa, 2003, Natureza Perversa, Amphibien Mit Schnabel, acrílica e grafite sobre tela. Crédito da Imagem: Sara Scholze e Matheus Furtado. Fonte: Arquivo dos autores. 
Esse exotismo explorado em Natureza Perversa ecoa os relatos de viajantes que vieram ao Brasil e descreveram um Novo Mundo repleto de excentricidades. Como Sílvio Marcus de Souza Correa discorre em 'Exotismo enquanto item cultural de exportação' (2004), “exótico” deriva de um termo grego alusivo ao estrangeiro, tendo sido incorporado à tradição cristã do Ocidente medieval para se referir ao que estava além de suas fronteiras, em especial o Oriente. Porém, a partir do século XVI, esse termo passa a ser atribuído às "terras e gentes" das Américas. Claude Kappler (1993) 3 e Carmen Lícia Palazzo (2009) demonstram que as navegações se inseriram em uma tradição europeia já consolidada:

Considerar os descobrimentos como um corte importante para uma abrupta entrada na modernidade ou entendê-los como sendo um resultado de mudanças pontuais na Europa não corresponde mais à análise que tem sido realizada pelos historiadores. Por outro lado, as imagens medievais do mundo, longe de se constituírem em um conjunto fechado de informações, eram múltiplas e variadas e estavam muito presentes na Europa dos séculos XV e XVI. Fundação de santuários à beira-mar, descendência lendária de certas famílias que se pretendiam herdeiras de casamentos entre cavaleiros e mulheres-sereias, canções de trovadores galegos atribuindo sentidos simbólicos ao oceano, cultura de navegação transmitida e intercambiada entre moçárabes e catalães, todo esse contexto se imbricava num mundo para o qual o movimento e o fazer-se ao mar eram uma realidade. (PALAZZO, 2009, p.48)

Dessa forma, monstros, híbridos e criaturas fantásticas que pertenciam à mirabilia medieval são propagados nessa construção de alteridade em que o Outro era descrito enfatizandose diferenças e estranheza. Assim, povos, fauna e flora brasileiras foram descritas em exuberância e plenas de exotismo pelos europeus.

No entanto, nesse início de modernidade também se buscavam alicerces científicos a partir da observação, coleta de espécimes e representação. As experiências vividas eram descritas e os interlocutores empenharam-se em tornar seus relatos convincentes, muitas vezes utilizandose de imagens. As representações iconográficas que integravam esses relatos tinham um caráter documental. Mesmo estando ainda repletas de "fabulosismos", como nos relatos de André de Thevet (1557) e Jean de Léry (1578), texto e imagem eram tratados como recursos de convencimento. E é exatamente nessa faceta que Natureza Perversa se aproxima dessas narrativas. Os estudos dos seres fantásticos ilustrados junto aos textos descritivos parecem esboços de observação de um viajante. Esses seres estão justificados no papel e transpostos às pranchas, o que lhes confere um aspecto também documental. 0 exotismo que há muito foi explorado está reexportado na obra de Walmor Corrêa. 0 artista cria um exótico "que o Outro não viu" 4.

3 KAPPLER,1993, pp.54-59

4 Essa expressão foi ressignificada a partir do artigo de Sílvio Marcus de Souza Correa aqui já citado. 
Por outro lado, em Biblioteca dos Enganos (2009) (fig. 2), exploram-se os relatos de Hermann von Ihering (1850-1930), evidenciando suas discordâncias com o natural. Esse importante naturalista chega ao Brasil em 1880 e se dedica a descrever e analisar a fauna brasileira. Porém, apesar da escrita austera, e de uma perspectiva menos mítica por se tratar de um viajante ao final do século XIX, von Ihering comete alguns equívocos em suas observações. Estes são identificados e explorados por Walmor em Biblioteca dos Enganos. O artista seleciona e ilustra em vinte e cinco livros esses seres já não tão fantásticos, mas com características peculiares que os fazem mesmo pertencer a supostas novas espécies. Assim, exibe-se ao espectador uma coletânea de representações acompanhadas dos relatos para que sejam observados. Dispostos em uma estante envidraçada (fig.3), acompanhada de uma pequena escada para melhor acesso, os livros apresentam um exótico enganoso, mas deslumbrante. É possível visualizar de perto os textos e representações, como se o próprio explorador tivesse disposto seus manuscritos para serem analisados. Como em Natureza Perversa, esse conjunto de elementos pode muito bem convencer o espectador de sua verossimilidade por meio da técnica e do discurso científico apropriado.

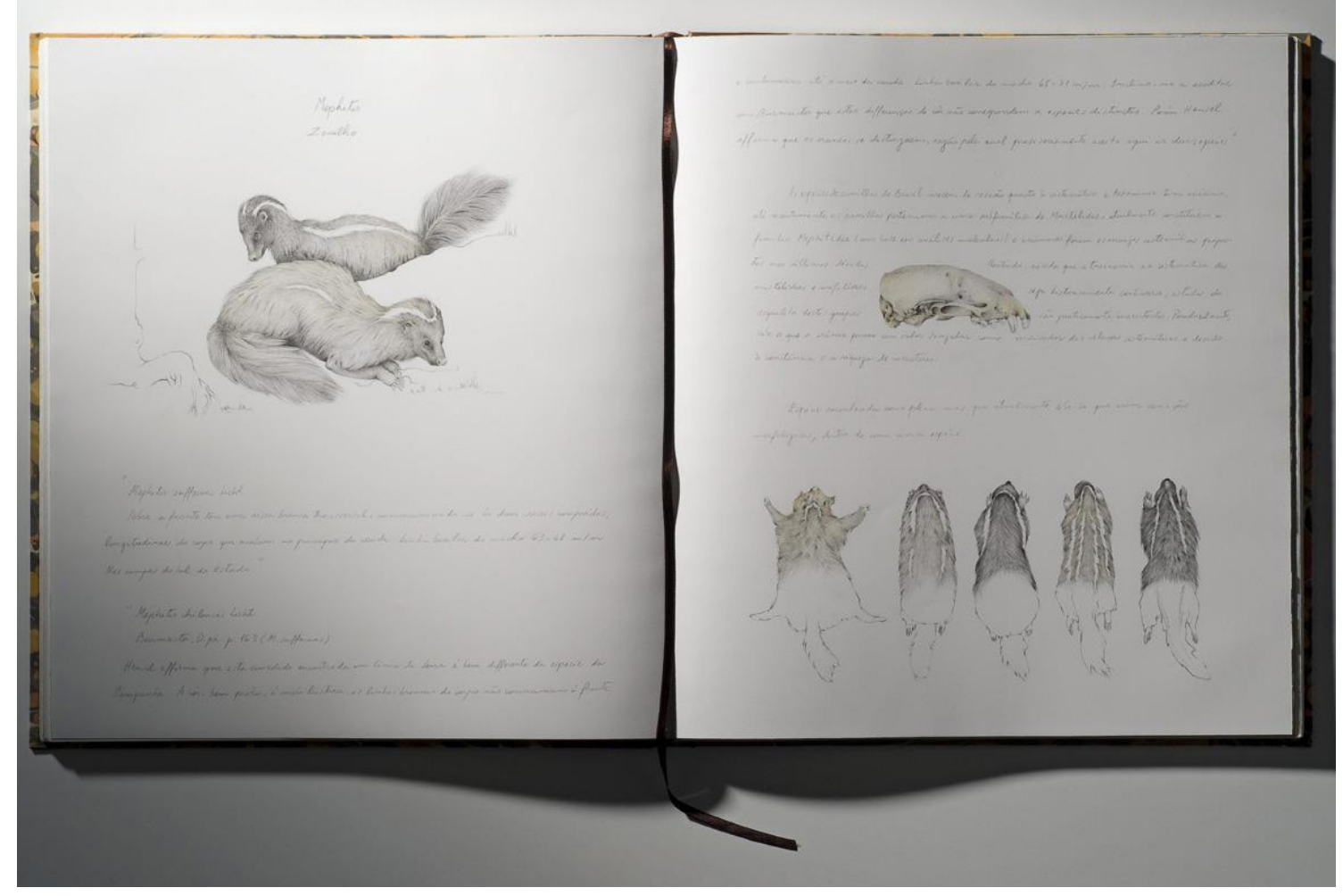

Figura 2 - Walmor Corrêa, 2009, Detalhe Biblioteca dos enganos, grafite sobre papel. Crédito da imagem: Instagram do artista. Fonte: https://www.instagram.com/p/BJIrdOiAo_c/ 


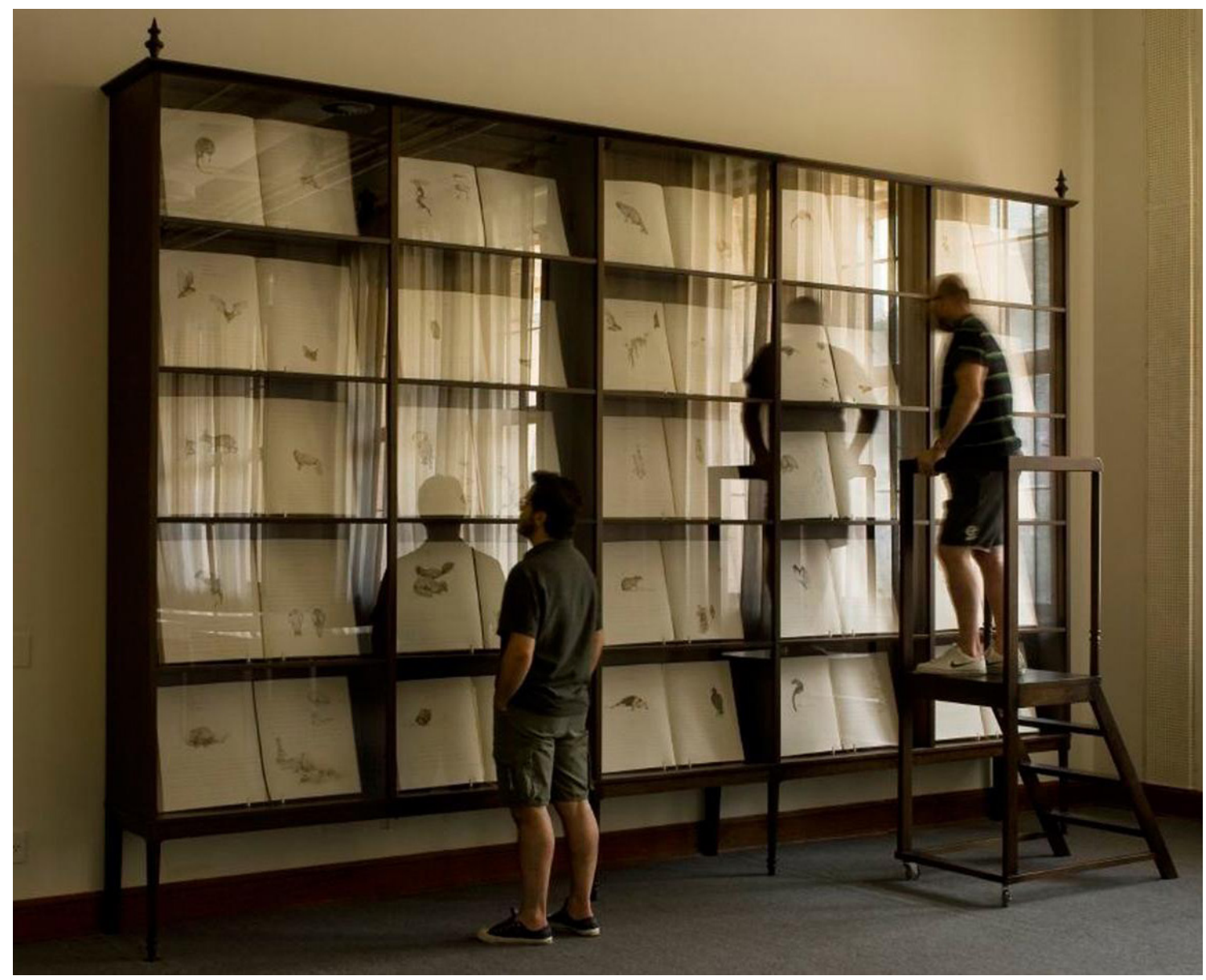

Figura 3.- Walmor Corrêa, 2009, Biblioteca dos enganos. Crédito da imagem: Instagram do artista Fonte: https://www.instagram.com/p/2YT4OIIrHM/

\section{Discursos expográficos: entre arte e ciência}

Em Memento Mori (2007), por sua vez, o artista explora a disposição dos objetos para nos remeter a um gabinete de curiosidades, trazendo mais uma camada significativa ao espectador. Essa instalação possibilita o percurso em meio a redomas que abrigam frágeis esqueletos fantásticos. Assim como em Natureza Perversa, em um relance tais seres parecem naturais, porém no olhar atento, é possível notar novamente o jogo de impossibilidades. As redomas localizadas no centro desse curioso ambiente entoam delicados sons e contribuem para o movimento em suspenso em que tais criaturas se encontram (fig. 4). Essas posturas são fascinantes. Dança do acasalamento? Recurso montado para cativar? Qual teria sido o real propósito desses movimentos? São perguntas que a obra permite ao observador elaborar, apesar de se tratar de animais que não necessariamente existiram. Ao fundo, cinco atlas anatômicos os quais apresentam o funcionamento interno dos seres folclóricos: Curupira, Ipupiara, Ondina, Capelobo e Cachorra da Palmeira. Neste mesmo ambiente, veem-se híbridos e mitos colocados em ambivalência com a ciência. 


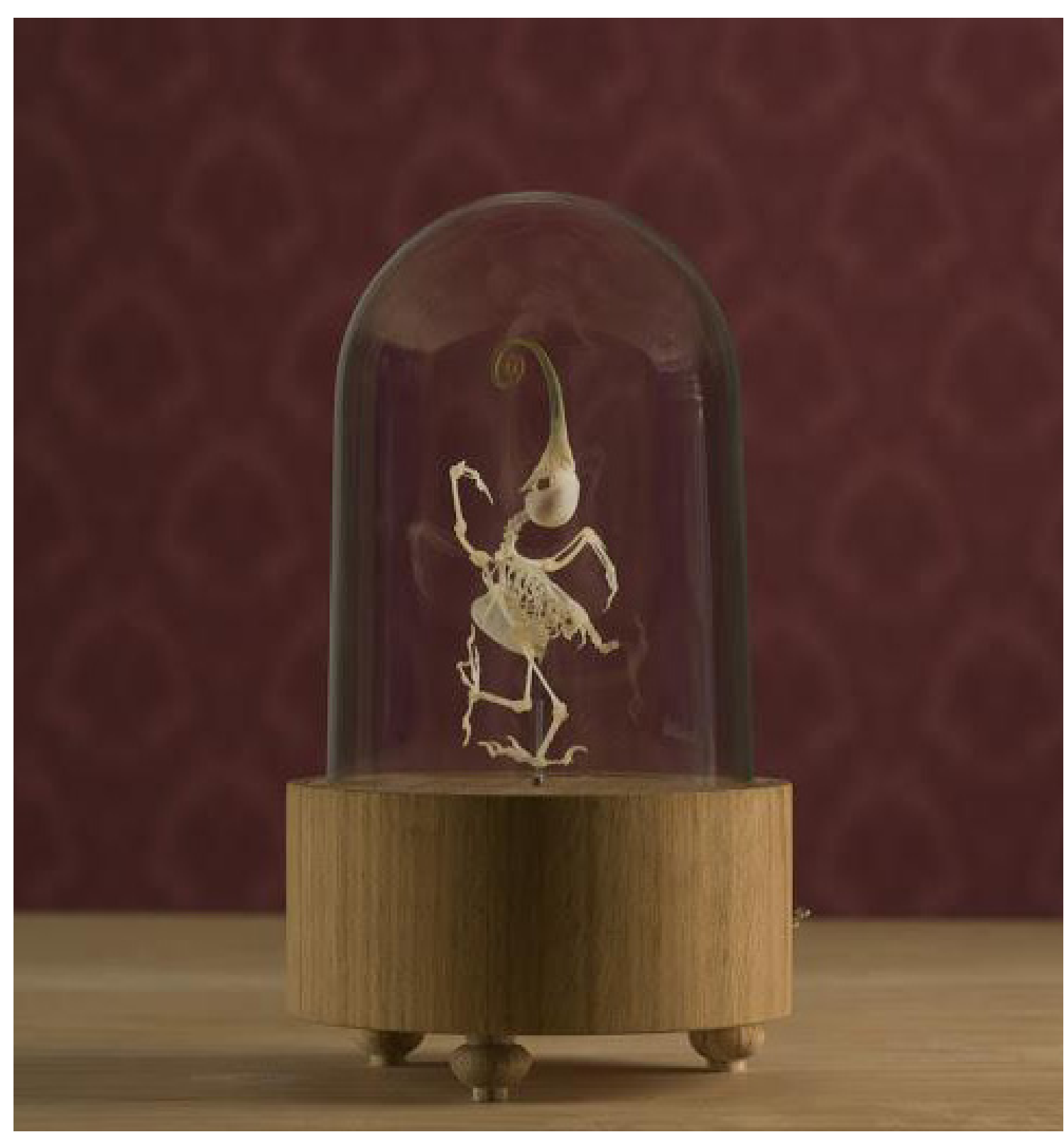

Figura 4 - Walmor Corrêa, 2007, detalhe Memento Mori, ossos, resina, vidro e madeira. Crédito da imagem: Instagram do artista. Fonte: https://www.instagram.com/p/BSL2uwcl0EV/

Memento Mori (fig. 5) evidencia essa relação entre imaginário e científico e o que engaja não é apenas a forma, mas o processo de compreensão dela, bem como o discurso museológico em torno de sua exibição. Parte do trabalho de deslumbramento nos animais irreais que ele constrói está justamente na apropriação de métodos de disposição de objeto museal. Os museus, especificamente os de História Natural, desenvolveram métodos científicos, processos, técnicas para acondicionamento, disposição, trajeto e exibição de seus elementos. Não há maior 
deslumbramento, ou melhor impacto visual em uma instituição museológica desta tipologia, que no encontro com a reconstituição do esqueleto de um animal em tamanho real. É a este tipo de impacto que este corpus de Walmor remete. As obras em questão instigam fascínio, pois tratam do exotismo tão bem explorado pelos relatos, gabinetes de curiosidades e posteriormente, Museus de História Natural.

Figura 5 - Walmor Corrêa, 2007, Instalação Memento Mori. Crédito da imagem: Instagram do artista Fonte: https://www.instagram.com/p/BStiBRJLHTD/ 


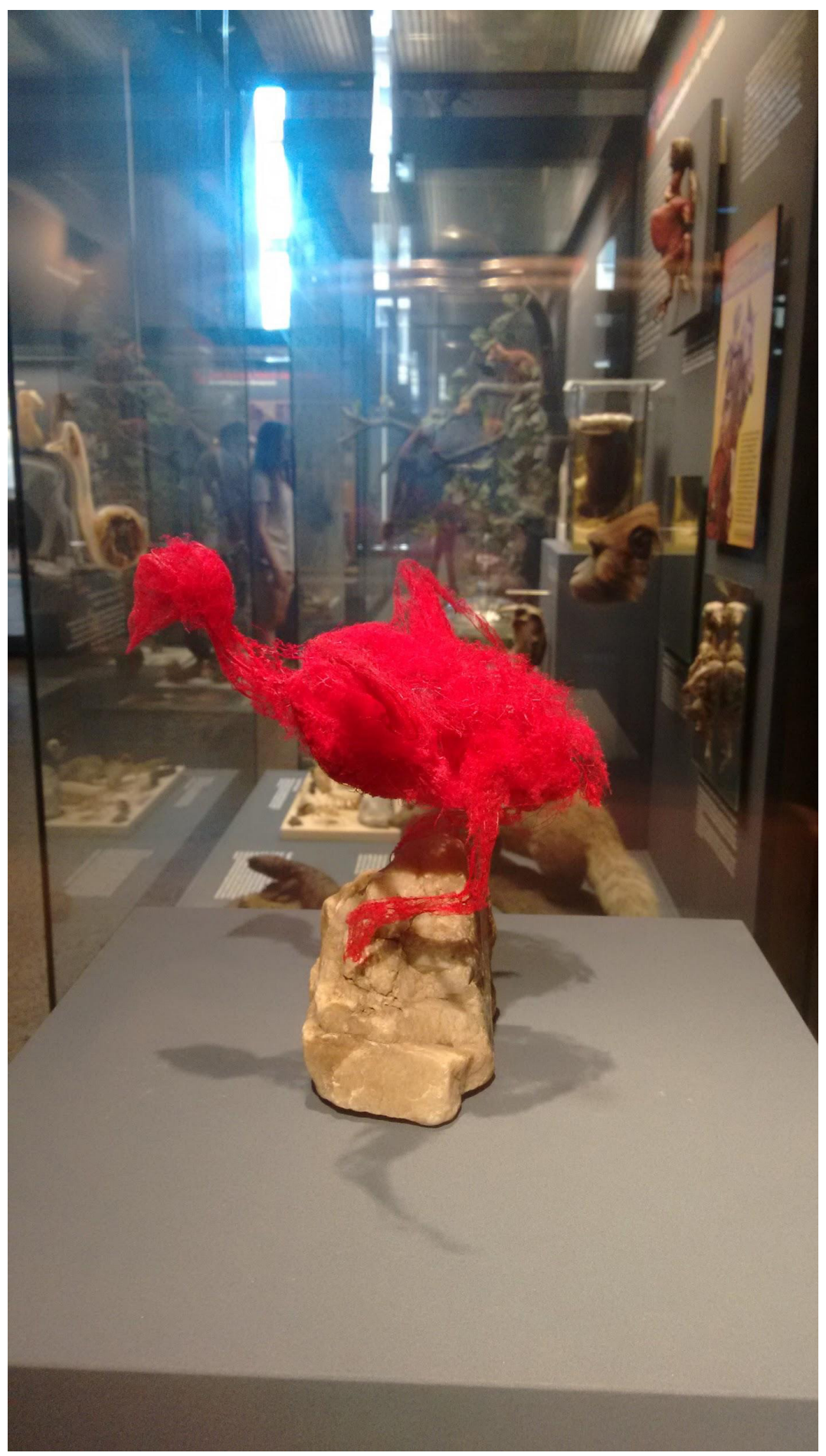

Figura 6 - Técnica de reconstituição e preservação por preenchimento de vasos - pássaro, 2017, Museu de História Natural de Berlim. Crédito da Imagem: Sara Scholze e Matheus Furtado. Fonte: Arquivo dos autores. 
Apesar de alguns autores garantirem que os Museus de História Natural hoje eliminaram esse espectro do "assombro" para as suas exposições, há de se considerar o desconhecimento e espanto com os resultados e técnicas dos objetos que seguem dispostos em suas coleções. Para o público, por exemplo, no Museu de História Natural de Berlim com seus modelos, esqueletos e dinossauros, a coleção de molhados visitável, e o espécime de pássaro feito por corrosão, são sim elementos fantásticos, que deslumbram o olhar e que, ao mesmo tempo, engajam pelo valor estético e alcance do conhecimento científico. No seguinte exemplo, temos um objeto exposto neste museu (fig. 6). Trata-se de uma reconstituição, uma ideia de pássaro exclusivamente composta a partir da técnica de corrosão, na qual há um processo de preenchimento do sistema circulatório do animal com uma resina sintética, plástica ou látex. Nesse processo, mantém-se o corpo do animal ainda quente, e o coração pulsando para que a resina alcance todos os capilares. Ao esfriar, o animal é disposto na posição desejada e imerso em um tanque com ácido, que corrói todo material orgânico exceto a resina. Tal técnica permite ao observador visualizar os milhares de rizomas e vasos do sistema circulatório que foram presentes em seu corpo. Esse intrincado de veias, preservado pelo preenchimento, se assemelha àquele das estruturas pensadas e elaboradas pelo artista em Memento Mori, ou Natureza Perversa. Ele se coloca nesta mesma linguagem expositiva: Uma redoma que separa o objeto, um elemento de ciência que se configura pela claridade, pela capacidade de observação detalhista e atenta. É interessante notar que o objeto exposto pelo museu de Berlim tampouco se constitui de um pássaro, é quase artístico, como apenas uma ilusão, das entranhas se tem uma ideia de "composição" de um pássaro.

O animal, propriamente dito, é composto por uma expressiva complexidade de sistemas, o que aqui se apresenta é, na verdade, uma simplificação que dá ideia da forma. Sabemos que é um pássaro, mas sem a legenda não se tem uma ideia real de qual sua espécie, sua cor, sua postura (há um motivo para ela? Escolha do taxidermista?). E isso faz dele não menos que fantástico. Este pequeno recorte do museu de Berlim permite um fascínio com o interior - deslumbramento com aquilo que compõe o animal anatomicamente, o que está diretamente ligado ao discurso científico, do mesmo nível que as imagens e objetos do artista. Adentrar em meio às obras de Walmor é explorar o mesmo assombro, pois os esqueletos primorosamente criados permitem o espanto ao perceber-se o paradoxo entre o discurso documental e o ficcional: seja por uma das suas composições de pássaro em Memento Mori, ou mesmo pelos seres folclóricos apresentados como uma janela para o que se veria por dentro - numa proposta de lição anatômica - tecidos, órgãos, sistemas, funcionamento. Esses elementos dizem respeito ao âmbito da ciência, mas aqui contaminam o trabalho de arte.

Ambos os objetos cercam o imaginário, se associam diretamente ao conceito de admiração com o diferente, e neste caso, com o estranho que habita o mundo natural. Sua exposição, disposição e lógica de encanto dar-se-iam, comparativamente, quase como partes de uma coleção em um gabinete de curiosidades dos séculos XVI/XVII. Historicamente possuidores deste papel de deslumbrar o público, os gabinetes compunham-se com as maravilhas descobertas, com as estranhas criaturas e com os diferentes espécimes adquiridos. A proposta de Walmor Corrêa parece ser de atrelar sua obra com o ideal imagético exótico que se expunha nessa cultura da "curiosidade" fantástica: 
[...] Os objetos existentes no gabinete de Borel, assim como em outros, carregam muito do maravilhoso, do fabuloso, do curioso. Monstros de duas cabeças, monstros marinhos, fragmentos de múmias, anomalias animais, chifres de unicórnios, e outros, mostram o universo maravilhoso, fantástico, existente nos gabinetes. Assim como as antiguidades greco-romanas mostram um passado ideal, os instrumentos científicos, como lunetas, microscópios, globos terrestres, instrumentos astronômicos, mostram a engenhosidade da natureza humana [...]. (RAFFAINI, 1993. p.160)

Os gabinetes estão repletos dessa atmosfera fantástica que se constituiu no imaginário ocidental desde a Idade Média. Eles apresentavam um recorte do mundo, sempre extremamente diverso e com um propósito universal. Há uma tendência de relatar o máximo possível, de trazer o máximo de exemplares possível e de organizar o melhor possível aquilo com que os exploradores se depararam, ou melhor, disseram se deparar.

Na prática, é nesse limiar entre ciência e fantasia, similar ao dos gabinetes europeus, que o artista explora as possibilidades de suas obras. Ele constrói esse discurso se valendo tanto de um imaginário expositivo, quanto imagético. O que um viajante do século XVI afirma ter visto, um gabinete possui, um artista de fato constrói e expõe. Esse aspecto carrega com mais significado os trabalhos e as noções aqui entendidas como fundamentais para a construção desse deslumbramento. Se o Museu de História Natural, nos dias de hoje, aparenta não ser mais capaz de impressionar o visitante, o "cientificismo fantástico" dos objetos e imagens no trabalho de Walmor Corrêa parece garantir essa reação. As ossadas dançantes, em redomas, de animais que não existem (abertas, claras e intrincadas) e as imagens de estudos anatômicos (com descrições, detalhamentos e aparente estudo) formam uma conexão entre essa memória dos Cabinet des curiosités, entre a linguagem ainda hoje mantida pelas instituições museológicas de História Natural e a produção artística que se coloca num processo de materialização no tempo. Valorizando e reconfigurando a imagética para a simbologia da tradição, do exótico e do fantástico.

Se, como nos mostra Didi-Huberman (2013), a imagem anacroniza a história, esses objetos, por uma lógica simples de figurarem neste espaço misto, anacronizam tanto a ciência quanto o seu espaço de apresentação. Sobrevivem formas de compreensão do mundo, na mesma medida em que sobrevivem os objetos de museus. Ainda existem chifres de unicórnios e leprílopes ${ }^{5}$ em $^{2}$ diversas coleções. Eles podem não ser mais entendidos como um dia foram - recortes de um mundo exótico, fabuloso e ainda inexplorado, que urge por uma organização e explicação - mas, são sim entendidos como um recorte do passado, que é fonte infinita de admiração e encantamento seja para artistas ou visitantes.

Umberto Eco mostra em seu reconhecido História das Terras e Lugares Lendários (2013), o papel que o discurso da maravilha tem no imaginário. Tal discurso tinha também a função de agregador social e essa função se exprime na tendência de exibir em um único espaço o universo

5 Animal fantástico composto de uma lebre com galhadas de cervos/antílopes, comum em gabinetes de curiosidade da Europa Moderna. 
diferente, incrível, inalcançável, ainda que existente. O que é interessante entender é a busca pelo maravilhoso, pelo raro. E não uma valorização do comum. No caso não é só mais um animal taxidermizado, não é só um pequeno esqueleto em redoma, mas é um esqueleto de um animal que "dança", que se encontra em uma pose muito específica. Tal perspectiva é, como já citado, uma questão chave no discurso do maravilhoso dentro de um Cabinet. 0 que se procura exibir é a raridade, é a fixação pelo estranhamento e impacto pelo diferente e mágico.

Ainda hoje se compram miudezas e lembranças para demarcar o valor ou significado de uma viagem. A construção de um imaginário de viagem se dá pelos relatos passados, e em determinado momento, passa a ser pela memorabília acumulada e trazida para a observação dos demais, recorte de outro mundo:

[...] não se deve esquecer que viajar não é apenas ver, observar e contar, mas também ouvir e memorizar as histórias de algum hábil contador encontrado por acaso durante a viagem. E como nas Mil e uma noites, em que as narrativas muitas vezes se encaixam umas nas outras, o relato de viagem é adornado com diversos contos ou narrativas de substrato mítico que o tornam atraente. (KAPPLER, 1993, p. 103)

É nessa lógica que se inserem os objetos que deslumbraram os olhos dos mecenas (príncipes, ricos burgueses) colecionadores de miudezas no século XVI; dos visitantes e proprietários dos quartos de maravilhas dos séculos XVIII e deste artista brasileiro que hoje olha para essa herança e produz um elemento próprio. Assim, consolida-se uma proximidade entre o ideal fantástico, o ideal científico e o ideal narrativo e o ideal expositivo.

\section{Considerações finais}

O que é esse deslumbramento científico? Tudo leva a crer que é em essência a própria obra de Walmor Corrêa. A sua preocupação com a estética científica e a construção de uma percepção singular dessa anatomia fantástica produzem por si só uma noção muito específica de como atrair o observador. Mais do que recursos estéticos, as escolhas imagéticas do artista nos remetem a uma associação com o tempo, no âmbito da memória e do imaginário, e constituem um trabalho significativo.

Ao nos remeter aos relatos dos viajantes e suas narrativas documentais, repletas de assombro e encantamento ou aos gabinetes de curiosidades, compostos de espécimes ditos raros e objetos que pertenciam às aventuras em lugares inóspitos e exóticos, as obras de Walmor possibilitam relações que vão para além do próprio deslumbramento com suas formas. Elas permitem questionar a identidade construída ao Novo Mundo e questionar as certezas da ciência a partir da visualidade. Os híbridos e pequenos enganos apresentados pelo artista suscitam a curiosidade, bem como o interesse pelas impossibilidades. A experiência como espectador nessas três obras permite dar novos significados ao presente, pois conforme afirma Didi-Huberman (2015, p. 16): “Diante de uma imagem - por mais recente e contemporânea que seja -, ao mesmo tempo o passado nunca cessa de se reconfigurar, visto que essa imagem só se torna pensável numa 
construção da memória [...]”. Memória esta que habita no exótico e no deslumbramento de um passado e que é evocada no presente do espectador que vivencia cada uma dessas obras.

Portanto, é possível identificar contaminações do passado, bem como apagamentos na obra de Walmor Corrêa. São esses elementos dos quais o artista se vale para produzir seus trabalhos. É por pensar e explorar cada vez mais esse reino do fantástico, do exótico e da memória que o artista constitui uma relação profunda e interdisciplinar com a ciência, a arte e a história. As obras de Walmor parecem ter se configurado a partir de "[...] um nó de anacronismos, essa mistura de coisas passadas e coisas presentes" (DIDI-HUBERMAN, 2013, p. 45) e, dentro das obras apresentadas, esses campos são tão bem elaborados que um não vigora sem o outro.

Esse sobrevivente imaginário fantástico é um diálogo direto com os aspectos exemplificados por Le Goff:

[...] Mas vejo o contrário no ocidente medieval: há uma desumanização do universo que se dirige para um universo animal, de monstros e bichos [...] há uma espécie de rejeição do humanismo [...] Insisto, enfim, nas fronteiras do maravilhoso. Tal como muitos fenômenos e muitas categorias, o maravilhoso não existe em estado puro: tem fronteiras permeáveis. (LE GOFF, 1994, p. 52)

É por valer-se de elementos permeáveis, impuros e advindos das categorias que o autor agrega como partes do conceito de imaginário (sonho, lenda, monstros, memórias incertas), que ele consegue consolidar tanto suas criaturas, quanto o fascínio do espectador. As obras aqui apresentadas se relacionam precisamente por habitarem esse reino do fascínio que foge do cotidiano, mas que possui fronteiras permeáveis. Do fantástico que salta do humanismo simples, que procura brincar com conceitos de áreas diversas e gerar um produto novo. Todas as obras e exposições apresentam-se como pertencentes ao reino das viagens maravilhosas; como recortes de estudos de ciências naturais e ilustração; ou ainda como artefatos desse ideal sobrevivente, que o artista nos convida a admirar, uma janela desses universos (sejam da Idade Média, das grandes navegações, das buscas por Preste João, enfim).

Os seres pensados pelo artista teriam sido extraídos de terras e lugares lendários? Ou teriam figurado na realidade natural e exótica do Novo Mundo (já não mais tão novo assim)? Essas são questões fundamentais no trabalho. $O$ universo de suspensão e de descrença explorado pelo artista é de tal maneira tangível, a partir das telas que parecem ter saído de lições de anatomia, pelas descrições detalhadas presentes em cada prancha, pela clareza das redomas que abrigam meticulosos esqueletos, ou seja, por um aparente cientificismo que permite materializar e documentar narrativas. 


\section{Referências}

CHEREM, Rosângela Miranda. Walmor Corrêa, um artista de fricções. In: ENCONTRO DA ASSOCIAÇÃO NACIONAL DE PESQUISADORES EM ARTES PLÁSTICAS “ENTRE TERRITÓRIOS”, 2010, Cachoeira BA, Anais do 19o Encontro da Associação Nacional de Pesquisadores em Artes Plásticas "Entre Territórios", p. 899-913. Disponível em: http://www.anpap.org.br/anais/2010/pdf/chtca/rosangela_ miranda_cherem.pdf. Acessado em 13/04/2021.

CORREA, Sílvio Marcus de Souza. Exotismo enquanto item cultural de exportação. In: MÉTIS: história \& cultura - v.3, n. 6, pp. 83-97, jul/dez, 2004. Disponível em: <http://www.ucs.br/etc/revistas/index. php/metis/article/view/1161/799> Acessado em: 15 fev. 2021.

DIDI-HUBERMAN, Georges. A imagem sobrevivente: história da arte e tempo dos fantasmas segundo Aby Warburg. Rio de Janeiro: Contraponto, 2013.

DIDI-HUBERMAN, Georges. Diante do Tempo - História da Arte e anacronismo das imagens. Belo Horizonte: Editora UFMG, 2015.

ECO, Umberto. História das Terras e Lugares Lendários. São Paulo: Ed. Record. 2013.

KAPPLER, Claude. Monstros, demônios e encantamentos no fim da Idade Média. São Paulo: Martins Fontes, 1993.

LE GOFF, Jacques, 0 imaginário medieval. Lisboa: Estampa, 1994.

OLIVEIRA, Ana Claudia de (Org.). Semiótica plástica. São Paulo: Hacker, 2004.

PALAZZO, Carmen Lícia. Entre mitos, utopias e razão: os olhares franceses sobre o Brasil (séculos XVI a XVIII). 2.ed. Porto Alegre: EDIPUCRS, 2009.

RAFFAINI, Patrícia Tavares. Museu Contemporâneo e os Gabinetes de Curiosidades. Rev. do Museu de Arqueologia e Etnologia. S. Paulo, 3: 159-164, 1993. https://doi.org/10.11606/issn.2448-1750.revmae.1993.109170 


\section{Sobre os autores}

Sara de Oliveira Lima Scholze é graduada em Artes Plásticas, bacharelado e licenciatura, pela Universidade de Brasília (2011) e mestre na linha Teoria Crítica e História da Arte pelo Programa de Pós-Graduação em Artes da Universidade de Brasília (2016). Atuou como pesquisadora no Programa de Estudos Medievais - PEM/UnB, tendo principal foco de estudo as representações medievais na contemporaneidade. Atua como pesquisa independente e seu trabalho de pesquisa possui dois eixos principais: a História da Cultura, iconografia e o processo de sobrevivência das formas, como conceituados por Aby Warburg e E. Panofsky; a Semiótica Visual e os processos de significação em pintura contemporânea, fundada nos princípios teóricos da semiótica discursive desenvolvida por Algirdas J. Greimas.

LATTES: http://lattes.cnpq.br/5094676309544466

ORCID: https://orcid.org/0ooo-0003-2451-0331

Matheus Silveira Furtado tem graduação em Museologia pela Universidade de Brasília, possui licenciatura em História e Mestrado em Artes também pela UnB. É curador e pesquisador pelo Programa de Estudos Medievais - PEM/UnB, seu principal foco de estudo são as representações medievais na contemporaneidade; realizou pesquisas em Instituições como o Museu de Cluny (Paris) e o Instituto Ricardo Brennand (PE) acerca das relações entre os Museus, seus discursos e a ldade Média.

LATTES: http://lattes.cnpq.br/8624778149155386

ORCID: https://orcid.org/0000-0002-2561-3554

Recebido em: 01-03-2021 / Aprovado em: 13-04-2021

\section{Como citar}

FURTADO, Matheus Silveira; SCHOLZE, Sara de Oliveira Lima (2021). Real fantástico? O deslumbramento científico em Walmor Corrêa. Revista Estado da Arte, Uberlândia. v.2, n.1, p. 75-89, jan./jun. 2021. https://doi.10.14393/EdA-v2-n1-2021-59544 